\section{ECCOMAS}

\section{Proceedia}

COMPDYN 2021

$8^{\text {th }}$ ECCOMAS Thematic Conference on Computational Methods in Structural Dynamics and Earthquake Engineering M. Papadrakakis, M. Fragiadakis (eds.) Streamed from Athens, Greece, 28 - 30 June 2021

\title{
A SEISMIC RISK ASSESSMENT FRAMEWORK FOR LOSS ESTIMATION OF CRITICAL INFRASTRUCTURE - HOSPITALS CASE
}

\author{
Basso P. ${ }^{1}$, Osmani S. ${ }^{1}$, Scolari M. ${ }^{2}$ and Valsecchi R. ${ }^{2}$ \\ RINA Consulting \\ ${ }^{1}$ Via Antonio Cecchi 6, Genova - Italy \\ e-mail: paolo.basso@rina.org - saimir.osmani@rina.org \\ ${ }^{2}$ Via Gran S. Bernardo, Strada 7, Palazzo R, Rozzano (MI) - Italy \\ e-mail: matteo.scolari@rina.org-ruben.valsecchi@rina.org
}

\begin{abstract}
In this paper, a framework developed for the seismic risk assessment and loss estimate of the Health-Care sector is described. The methodology herein presented derived from a wider study that refers to a multi-hazard (earthquake, hurricane, flood, landslide, rockfall, avalanche) and multi-asset (healthcare and energy infrastructure).

The loss estimate is based on the probabilistic modelling of hazards and asset vulnerability and an overall assessment of the impact generated from the suffered damage treated as a deterministic consequence of it.

Specifically, the total impact computation is based on the combined analysis of different aspects, such as physical damages, service reduction, and social impact. For the sake of completeness also the impact is evaluated per each aftermath level. It must be pointed out that in so doing the loss computed per each impact can be ensured as hazard independent.

An important role in the impact evaluation is also played by resilience. A simplified evaluation of preparedness and resourcefulness at asset and local level is performed to originate a set of resilience-based coefficients which, in turn, are used to influence the evaluation of the loss per each impact component and level of damage.

Finally, the Expected Annual Loss (EAL) is provided as the exponential relation between the probability of damage occurrence expressed as mean annual frequency, and the loss, expressed in economic terms. So, this relation can define the properties of damage occurrence and loss of each possible event. Thanks to the quantitative approach of the framework it can be seen how each risk aspect influence the curve properties, such as the horizontal stretch due to resilience influence on the loss degree and the vertical stretch due to vulnerability effect on the damage occurrence.
\end{abstract}

Keywords: Asset Integrity Management, Loss assessment, Probabilistic assessment, Expected Annual Loss, Territorial scale, Decision Support System 


\section{INTRODUCTION}

When assessing the risk posed by a certain hazard the first parameter to be qualified is its frequency of occurrence. The definition is deeply related to the relevant historical data for a given geographic reference. The determination of the hazard alone cannot be directly used if not correctly correlated in space and time.

The determination of the hazard starts from the qualitative depiction of a plausible threat scenario for which the occurring frequency is determined. The definition of exposure calls into play the time and spatial correlation as some areas might be more prone to a certain hazard rather than others (e.g. the threat of an earthquake is deeply correlated to the geographic location of an asset and the surrounding context).

Along with the determination of possible threats and relevant frequencies, the vulnerability of the asset shall be determined as well using a structural and logistics assessment.

The impact could be evaluated for different kind of assets as well as for different kind of targets. The weighted average of all the estimated impacts (damages) arising from the execution of a threat is called Impact.

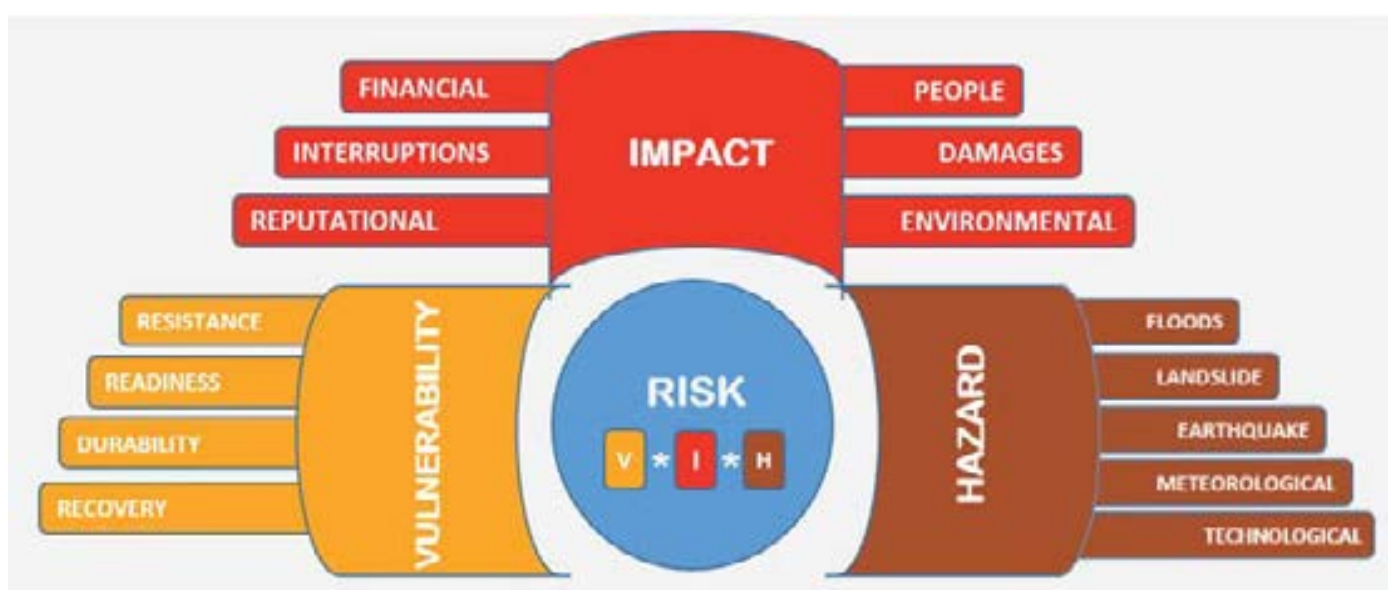

Figure 1: Key elements of Risk Assessment

\section{HAZARD ASSESSMENT}

In the proposed methodologies the Hazard is considered through the definition of the Hazard curves (Figure 2). They describe the frequency of occurrence of the Intensity Measure (IM) of a certain hazard (e.g. PGA for earthquake), allowing in this way extended and detailed analyses. For the Hazard data collection, it will be possible to consider the following sources:

- Literature Databases;

- National Codes (it provides the procedure to obtain the hazard curve, if available);

- Websites Databases;

- Thematic maps on hazard distribution produced at the national level.

In the case of Literature databases and National Codes, besides having the entire hazard curve, we can obtain a limited number of IMs with the associated frequency/probability of occurrence. In this case, the few data available (IMs) can be used to build up the hazard curve through a fitting process through power or exponential laws, following the procedure presented hereafter. 


\subsection{Hazard curve definition}

The Peak Ground Acceleration (PGA), expressed in g, are commonly given for 4 different percentage of exceedance in 50 years, which are commonly $2 \%, 10 \%, 50 \%$, and $68 \%$.

The hazard is often expressed in terms of exceedance probability, rather than in terms of exceedance rate (number of events per unit time). The exceedance probability is the probability that a certain intensity will occur at least once in a given period.

The two can be related using a concept called a Poisson process, which is a stochastic process that counts the number of events and the number of times in which they occur in a given interval. The relationship is explained in the following formula:

$$
G=-\ln (1-P) / t
$$

In which $G$ is the occurrence rate (i.e. events per unit time) that is expressed as the inverse of the return period $\mathrm{Tr}$, while $P$ is the probability of occurrence of at least one event in the considered period $t$.

Based on this formulation the occurrence rate, Mean Annual Frequency (MAF), and the return periods $(\mathrm{Tr})$ can be calculated considering a reference period $\mathrm{t}=50$ years:

$$
\begin{gathered}
M A F=-\ln (1-P) / 50 \\
T r=-50 / \ln (1-P)
\end{gathered}
$$

Therefore, The Mean Annual Frequency (MAF) and the return period (Tr) can be computed by the 4-given percentage of exceedance in 50 years (Table 1).

\begin{tabular}{ccc}
\hline $\begin{array}{c}\text { Probability } \\
\text { in 50 years }\end{array}$ & $\mathrm{Tr}$ & MAF \\
\hline$\%$ & $\mathrm{y}$ & $1 / \mathrm{y}$ \\
\hline 2 & 2475 & 0.0004 \\
10 & 475 & 0.0021 \\
50 & 72 & 0.0138 \\
68 & 40 & 0.0228 \\
\hline
\end{tabular}

Table 1: Mean Annual Frequency values (MAF) - Earthquake case

For each site is possible, by using the IMs (e.g. PGA for the earthquake) of the different return periods and the MAF, to define the hazard curve (Figure 2) by fitting the 4 points.

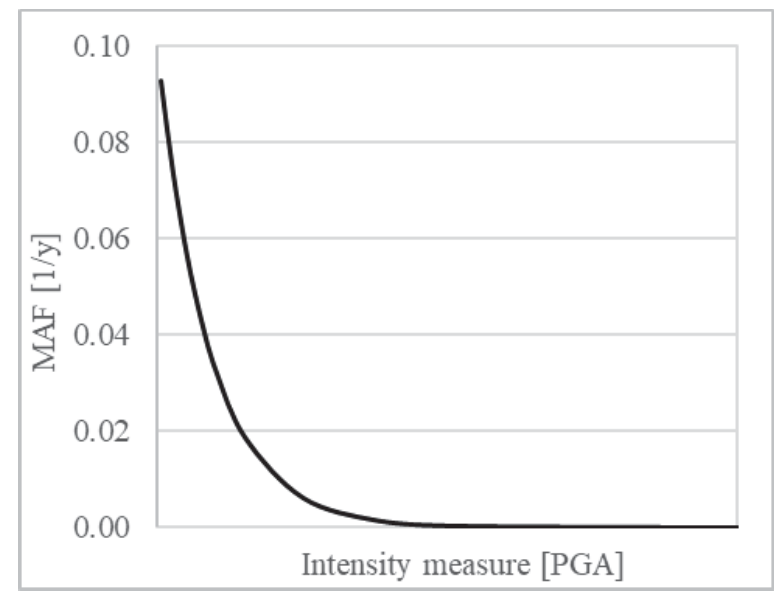

Figure 2: Typical Hazard curves for Earthquake 


\section{VULNERABILITY DEFINITION}

Vulnerability is a measure of asset damage/failure due to a hazardous event. As an alternative, it could be also defined as the target's inability to deter and withstand the specific disaster. The assessment can be defined considering three different factors: Geographical location; Hazard response; Target hardness.

The vulnerability assessment is made by an exhaustive Database generated through the knowledge from literature, internal resources or by directly inputting the fragility curves parameters, in case of ad hoc developed fragility curves.

For each asset category, 4 damage states are selected (DS1, DS2, DS3, DS4), defined to represent the most important probability of exceedance, following the Hazus [5] subdivision of damage levels.

\begin{tabular}{cc}
$\begin{array}{c}\text { DS1 } \\
\text { (Slight) }\end{array}$ & $\begin{array}{c}\text { Flexural or shear type hairline cracks in some beams and columns near joints or } \\
\text { within joints }\end{array}$ \\
$\begin{array}{c}\text { DS2 } \\
\text { (Moderate) }\end{array}$ & $\begin{array}{c}\text { Most beams and columns exhibit hairline cracks. In ductile frames, some of the } \\
\text { elements have reached yield capacity, showing larger flexural cracks and spall- } \\
\text { ing. Nonductile frames may exhibit larger shear cracks and spalling }\end{array}$ \\
\hline DS3 & $\begin{array}{c}\text { Some of the elements have reached the ultimate capacity. In ductile frames large } \\
\text { flexural cracks, spalled concrete and buckled reinforcement occur. The nonduc- } \\
\text { tile elements may experience shear or bond failures at reinforcement splices, or } \\
\text { broken ties or buckled reinforcement in columns, leading to a partial collapse }\end{array}$ \\
$\begin{array}{c}\text { The structure is collapsed or in imminent danger of collapse due to brittle failure } \\
\text { of nonductile elements or loss of frame stability. Approximately 13\%(low-rise), } \\
\text { 10\%(mid-rise) or 5\%(high-rise), respectively for low/mid/high-rise, of the area } \\
\text { of buildings, is expected to be collapsed }\end{array}$ \\
$\begin{array}{c}\text { DS4 } \\
\text { (Complete) }\end{array}$ \\
\hline
\end{tabular}

Table 2: Limit states description [5]

As can be seen in Figure 3 and Table 3, for each asset category is set 4 levels of damage, which represent 4 levels of criticality. For each damage state is defined:

- Percentage of damage, per each level and asset, which are stored in an internal database;

- The description of the visible effect on the facility per each damage level (Table 2).

This subdivision in 4 levels is useful to check out the probability of damaging and to know also the damage level that can be reached with this value of probability. The 4 levels are used in this analysis to reach a desirable level of simplicity, without losing the minimum level of accuracy required. Therefore, this kind of subdivision gives the possibility to set, among the different subsectors, different criticality levels depending on the specific asset considered.

In the following tables, characteristics (structural and temporal) and parameters (mean values and standard deviation) used respectively to select and define the fragility curves are listed.

\begin{tabular}{|c|c|c|c|c|c|c|c|c|c|c|}
\hline \multirow{2}{*}{ Asset } & \multirow{2}{*}{ Parameter 1} & \multirow{2}{*}{ Parameter 2} & \multicolumn{4}{|c|}{ Mean values $[\mathrm{g}]$} & \multicolumn{4}{|c|}{ Standard deviation } \\
\hline & & & DS1 & DS2 & DS3 & DS4 & DS1 & DS2 & DS3 & DS4 \\
\hline \multirow{6}{*}{ 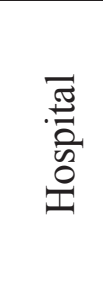 } & 1-3 storeys & pre-1950 & 0.09 & 0.18 & 0.30 & 0.42 & 0.78 & 0.74 & 0.73 & 0.73 \\
\hline & 4-7 storeys & pre-1950 & 0.02 & 0.15 & 0.24 & 0.29 & 0.97 & 0.69 & 0.67 & 0.67 \\
\hline & $8+$ storeys & pre-1950 & 0.07 & 0.19 & 0.37 & 1.24 & 0.74 & 0.66 & 0.64 & 0.64 \\
\hline & $1-3$ storeys & post-1950 & 0.12 & 0.29 & 1.67 & 2.17 & 0.75 & 0.71 & 0.70 & 0.70 \\
\hline & 4-7 storeys & post- 1950 & 0.10 & 0.21 & 0.86 & 1.70 & 0.66 & 0.64 & 0.64 & 0.62 \\
\hline & $8+$ storeys & post- 1950 & 0.10 & 0.27 & 1.58 & 4.26 & 0.63 & 0.60 & 0.59 & 0.53 \\
\hline
\end{tabular}


Table 3: Limit states description [7]

For the selection of the appropriate Fragility curve (Figure 3) many parameters are considered, such as the principal construction material, construction typology, year of construction, the presence or not of codes during the design phase of the asset, dimensions of the asset (e.g. footprint, ground floors, $\mathrm{n}^{\circ}$ of stories etc.).

A specific database is built with standardized unitary value to overcome the potential lack of information. So, starting from the main characteristics of the asset, the fragility function can be selected. In Figure 3 an example is shown.

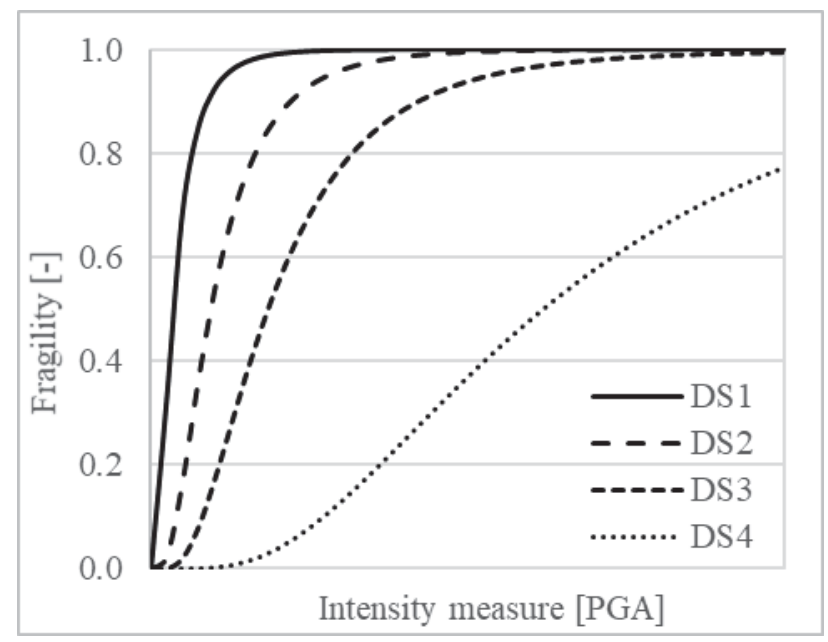

Figure 3: Example of fragility curves

\section{IMPACT ANALYSIS}

The Impact is defined as the presence of people, livelihoods, species or ecosystems, environmental functions, services, and resources, infrastructure, or economic, social, or cultural assets in places and settings that could be adversely affected by a hazard. Therefore, it can be seen as the scale of the consequences of a hazard.

The impact is normally quantified in the determination of damages and losses caused to stakeholders, environment and human life. In this particular study case, the analysis of the impact is based on the analysis of three different categories:

- Impacts on People (fatalities/injuries);

- impacts on the Physical System/Infrastructure (damages on the structures);

- impacts on Service continuity (interruptions/downtime).

The evaluation of each component is also provided in economic terms; in such a way the combination of the three is possible, providing a unique impact value.

\subsection{Impacts on People}

The analysis of the impact on the people $\left(\mathrm{IP}_{\mathrm{DSi}}\right)$ is based on the evaluation of the number of fatalities and injuries [6] due to the occurrence of a certain hazard. The methodology used is based on the definition of three categories: Death, Slightly injured, and Severe injured.

The evaluation is provided according to the relation carried out by Cimellaro et al. [1], in the paper the percentage of death and injured people is related to the damage state that occurred after the hazardous event. 
Basso P., Osmani S., Scolari M. and Valsecchi R.

\begin{tabular}{cccccc}
\hline & U.M. & DS1 & DS2 & DS3 & DS4 \\
\hline Death $_{\text {DSi }}$ & $\%$ & 0.000 & 0.000 & 0.0015 & 12.500 \\
\hline InjuryDSi $^{2}$ & $\%$ & 0.000 & 0.030 & 0.1005 & 22.500 \\
\hline
\end{tabular}

Table 4: Normalized human losses ratios for different damage state [1]

The number of deaths can be obtained by multiplying the death loss ratio shown above (Table 4) with the number of people inside the hospital:

$$
\text { Death }_{D S i}=\text { Death }_{D S i}(\%) \cdot \delta_{t} \cdot \text { People_in_hospital }
$$

In which DeathDSi (\%) is the percentage derived from Table 4, People_in_hospital is the number of people in the hospital, and $\delta_{t}$ is the coefficient of reduction that consider the effect of the asset preparedness on the people evacuation (section 5.1).

Furthermore, thanks to the Syner-G [2] a further distinction could be made on the injury. They are divided into slightly and severely injured through the severity injured ratio $\zeta$ that typically varies between $1 / 3$ and $1 / 2$ (in the evaluation $1 / 3$ is used).

It must be pointed out that some further consideration must be performed on the analysis of the severely injured. They are assumed to be the people which need surgical treatment, thus they are considered as the Hospital Treatment Demand, HTD, which must be compared with the Hospital Treatment Capacity per hours, HTC [2].

$$
H T D_{D S i}=\text { People } \cdot\left(1-\delta_{p}\right) \cdot \text { Severe_injured }_{D S i}(\%)
$$

In which $\delta_{p}$ is the percentage of people evacuated within the due time (section 5.2).

The people affected are obtained by the district density and the analyzed area:

$$
\text { People }=\cdot \text { density }_{\text {distric }} \cdot \text { Area }
$$

The area used for this evaluation should be selected as the minor between the influence area of the hospital and the hazard area:

- Influence Area: A rough area of influence per each hospital is evaluated simply implementing the Voronoi Diagram using the hospitals as discrete points;

- The hazard area rather is defined as the one on which the considered hazard produces the selected damage. It can be defined considering the attenuation function of the hazard intensity, starting from the studied point. In literature several examples can be found, e.g. for the earthquake, this area is defined according to the empirical attenuation formula for the PGA [8]:

$$
\begin{gathered}
\log (a)=\alpha+\beta \cdot M-\log (r)+b \cdot r \\
r=\sqrt{d^{2}+h^{2}}
\end{gathered}
$$

Where $\mathrm{d}$ is the distance from the source which can be computed per each damage state trough a solver algorithm. The other parameters are: $a$ is in $\mathrm{g}, \alpha$ is $-1.09, \beta$ is $0.238, b$ is 0.0005 , and $h$ is 6.0 for horizontal PGA [8].

\begin{tabular}{cccccc}
\hline & U.M. & DS1 & DS2 & DS3 & DS4 \\
\hline Severe injured & $\%$ & 0.00 & $\zeta \cdot 0.03$ & $\zeta \cdot 0.1005$ & $\zeta \cdot 22.50$ \\
\hline Hazard area & $\mathrm{km}^{2}$ & \multicolumn{3}{c}{ Empirical evaluation of affect area } \\
\hline Hospital influence area & $\mathrm{km}^{2}$ & \multicolumn{4}{c}{ Voronoi Diagram } \\
\hline
\end{tabular}

Table 5: Hospital Treatment Demand evaluation 
The hospital Capacity per one day is computed considering the operative functionalities decay after the hazardous event [2].

$$
H T C_{D S i}=\frac{1}{\delta_{i n t}} \cdot \frac{\gamma_{1, D S i} \cdot \gamma_{2}}{t_{m}} \cdot 24 h
$$

Where $\gamma_{1, D S i}$ is the number of operating theatres which remain operative after the hazardous event, $\gamma_{2}$ is a Boolean function (equal to 1 if the system "survives" and to 0 otherwise), $t_{m}$ is the mean duration of a surgical operation, measured in hours (in this study this value is assumed equal to $2 \mathrm{~h}$ according to [2]), and $\delta_{\text {int }}$ is the coefficient that considers goodness of the internal coordination among facilities and department (section 5.4).

The number of operating theatres $\left(\gamma_{1}\right)$ is evaluated by considering the decay of the capacity of the hospital:

$$
\gamma_{1, D S i}=O T \cdot\left(1-\text { Service }_{D S i}\right)
$$

In which $O T$ is the number of operating theatres and Service $_{D S i}$ represent the percentage decrease of the hospital service, which can be derived from literature per each damage state.

The economic loss due to the impact on the people (IPDSi) can be evaluated by considering two different aspect:

- The "direct" death due to the event (computed by people inside the hospital).

- If HTD > HTC, the "indirect" death is determined as the severely injured people that cannot have access to the surgical treatment (computed using the people inside the socalled influence area) [2]. life.

Therefore, the number of human life losses can be multiplied by the mean value of human

$$
I P_{D S i}=\left\{\text { Death }_{D S i}+\left[\left(H T D_{D S i}-\delta_{E 2} \cdot \text { Share } P \cdot N_{-} \text {Hospital }\right)-H T C_{D S i}\right]\right\} \cdot \text { Life Value }
$$

In which Life value is expressed in $\mathrm{k} \$$ person and $\delta_{E 2}$ represents the coefficient related to hospital redistribution capacity during an emergency (section 5.6).

Share_P represent the sharing capacity between two hospitals, calibrated considering the average number of patients that can be relocated during an emergency. It sets equal to 35, based on the experience derived from the Italian 2020 healthcare crisis due to Covid-19 [13].

N_Hospital is the number of hospitals within the sharing distance, which in first approximation is set to $30 \mathrm{~km}$. Such value is computed by the hospital influence area, according to the following formulation:

$$
N \_ \text {Hospital }=2^{\left[\left(30 \mathrm{~km} / 2 \sqrt{A_{\text {inf } / \pi}}\right)+2\right]}
$$

To have a better understanding of the approach a simplified scheme is listed below. 


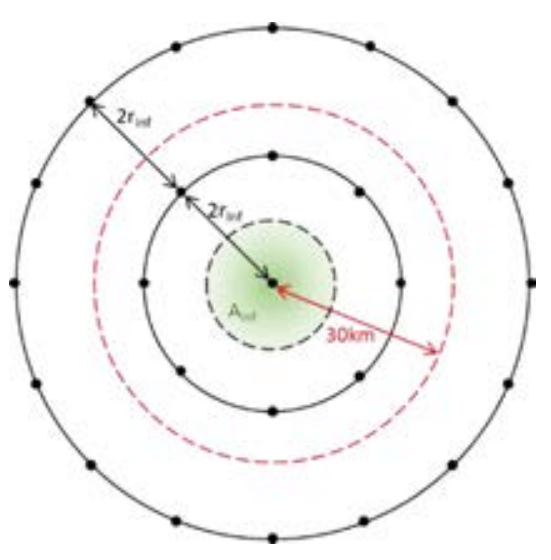

Figure 4: Hypothetic sharing scheme

- The points in this scheme represent the hospitals.

- $\mathrm{A}_{\text {inf, }}$ which is drawn in green is the area of influence of each hospital. It can be computed as the mean of the district/province.

- $r_{\text {inf }}$ is consequently the radius of influence.

- $30 \mathrm{~km}$, as said before, represents the distance over which the sharing is no more feasible.

Therefore, the value inside the round bracket should be rounded down. Since inside the square bracket, an integer number must be used, because it represents the number of rings of hospitals inside the sharing distance.

\subsection{Impacts on Physical system}

The impact on the physical system (ID ${ }_{\text {DSi }}$ ) can be defined as the impact cost due to the direct damage experienced by the facility [6]. The economic loss can be ease defined as follow:

$$
I D_{D S i}=\text { Damage }_{D S i}(\%) \cdot \text { Reconstruction_Cost }
$$

In which DamageDSi (\%) is the damage value associated with each damage state, that can be derived from literature per each damage state [3], while Reconstruction_Cost is the expected cost to take back the asset to full operation, comprehensive of both structural and equipment cost. It can be calculated in two different way: directly calculated from the construction cost or indirectly derived from dimension and the unitary cost, taken from the literature [4].

\subsection{Impacts on Service continuity}

The impact on service continuity ( $\mathrm{IR}_{\mathrm{DSi}}$ ) can be related to the effects on the population, of the reduction of the service due to damage [6]. The evaluation is based on the information on the mean recovery time and service reduction per each damage state, according to the relation carried out by Cimellaro et al. [1].

The additional time that the people need to get access to the health care facilities is the base of the economic loss evaluation. As can be seen in the following formula the recovery is considered as a linear function:

$$
I R_{D S i}=\delta_{r e c} \cdot t_{r, D S i}\left[\text { Service }_{D S i}(\%) \cdot\left(\text { Size }-\delta_{E 1} \cdot \text { Mobile_P }_{-} \cdot G r\right)\right]\left(2 t_{\text {dist }} \cdot \text { Value }_{\text {time }}\right)
$$

Where ServiceDSi (\%) is the percentage of service reduction per each damage state, that can be derived from literature per each damage state, $t_{r, D S i}$ is the recovery time, that can be derived from literature per each damage state, $t_{\text {dist }}$ is the time needed to reach the nearest facility per each damage state, Size, it must be expressed by the characteristic unit of measure (number of people), Value $e_{\text {time}}$, it is the value of the people time, $\delta_{E l}$ represents the coefficient related to the accessibility to the eventual mobile health care post (section 5.5), $\delta_{\text {rec }}$ is the coefficient that considers how the recovery is carried out (section 5.3), Mobile_P represent the number of patients that can be endorsed by this mobile healthcare post, that usually has a capacity of 25 beds [14], and $G r$ represents the ratio among bed capacity and the average people inside the hospital. 


\section{Total impact}

The total impact ( $\mathrm{I}_{\mathrm{TOT}, \mathrm{DSi}}$ ) is evaluated by summing the different economic losses categories per each damage state, as shown in the following formula:

$$
I_{T O T, D S i}=I P_{D S i}+I D_{D S i}+I R_{D S i}
$$

In which $I P_{D S i}$ is the Impact on People economic loss, $I D_{D S i}$ is the Impact on Physical System economic loss, and $I R_{D S i}$ is the Impact on Service Continuity economic loss.

\section{RESILIENCE}

The term resilience means the ability to prepare for and adapt to changing conditions and withstand and recover rapidly from disruptions, it includes the ability to withstand and recover from occurring threats or incidents.

The resilience is evaluated using a score index (from 0 to 3 ). Three main categories are considered for its definition:

- Preparation (planning in advance), which consider the existence/status of emergency plans (P1) and the frequency of training courses/exercise (P2), the existence of insurance cover (P3), the existence of backup systems (P4), the community experience on the hazardous event (P5), and the warning time before the hazardous event (P6).

- Internal resourcefulness considers the effectiveness and availability of resources, such as early warning system and/or specific countermeasure (Int1), materials to offset the loss (Int2), and coordination with facilities/department of Hospitals (Int3).

- External resourcefulness in which are considered the existence of the external agreement and coordination plants with other subjects: institution and/or organizations (Ext1), public units and/or local government institutions (Ext2), provincial health directorate institutions (Ext3), and special treatment units of hospitals (Ext4).

Resilience is considered in the risk assessment through the evaluation of resilience ( $\left.I_{\text {Res }}\right)$. The score of each asset is therefore evaluated developing a resilience matrix (Table 6), in which the score can be obtained for every single hazard or as the total one. The final value of the resilience index is computed by a weighted average [9]:

$$
I_{\text {Res }}=\sum_{i=1}^{3} R C_{i} \cdot W_{i}
$$

Where $R C_{i}$ is the resilience component score and $W_{i}$ is the weight of each component.

\begin{tabular}{ccccc}
\hline Earthquake & Preparation & $\begin{array}{c}\text { Internal Re- } \\
\text { sourcefulness }\end{array}$ & $\begin{array}{c}\text { External Re- } \\
\text { sourcefulness }\end{array}$ & $\mathrm{I}_{\text {Res }}$ \\
\hline Score [0 to 3] & 1.76 & 3.00 & 3.00 & $84 \%$ \\
\hline Weight & 0.38 & 0.316 & 0.304 & 1 \\
\hline
\end{tabular}

Table 6: Resilience analysis matrix (example of compilation)

It is important to note that the Resilience Index is a way to compare the levels of resilience of critical infrastructures and to help the prioritization of investment [9] together with the just explained Expected Annual Loss.

This resilience, beyond the assignment of the so-called resilience indicator, are also used to affect the impact analysis. Some resilience coefficients are defined to consider these resilience factors also into the impact analysis, as can be seen in the following table. 


\begin{tabular}{|c|c|c|c|c|c|c|c|c|c|c|c|c|}
\hline \multirow{3}{*}{$\begin{array}{l}\text { Resilience } \\
\text { Indicators }\end{array}$} & \multirow{2}{*}{\multicolumn{4}{|c|}{ Preparation }} & \multicolumn{8}{|c|}{ Resourcefulness } \\
\hline & & & & & \multicolumn{4}{|c|}{ Internal } & \multicolumn{4}{|c|}{ External } \\
\hline & $\mathrm{P} 1$ & P2 P3 & $\mathrm{P} 4$ & P5 P6 & Int1 & Int2 & Int3 & Int4 & Ext1 & Ext2 & Ext3 & Ext4 \\
\hline IP & $\delta_{\mathrm{t}}$ & $\delta_{\mathrm{t}}$ & & $\begin{array}{ll}\delta_{\mathrm{p}} & \delta_{\mathrm{p}} \\
\end{array}$ & & & $\delta_{\text {int }}$ & & & & $\delta_{\mathrm{E} 2}$ & $\delta_{\mathrm{E} 2}$ \\
\hline \multicolumn{13}{|l|}{ ID } \\
\hline IS & & & $\delta_{\text {rec }}$ & & $\delta_{\text {rec }}$ & $\delta_{\text {rec }}$ & & & $\delta_{\mathrm{E} 1}$ & $\delta_{\mathrm{E} 1}$ & & \\
\hline
\end{tabular}

Table 7: Resilience indicators dependency on the resilience aspects and their influence on the impact on people (IP), on the physical system (ID), and service continuity (IS)

\section{1 $\delta_{\mathrm{t}}$ : Preparedness - Evacuation efficiency inside the asset}

The evaluation of the casualties should consider the capacity of the people inside the asset to evacuate in the best way. Usually, this capacity can be related to the existence or not of the emergency plan and also its quality. The second aspect is the training. Also, in this case, this can be asses analyzing not only its occurrence or not, but also the frequency at which it is set.

In the work done by Li et al. [10] the evacuation efficiency is assessed through two factors:

- $\quad \mathrm{k}_{\mathrm{S}}$ is defined as the attraction capacity of the exit to the people inside the asset;

- $\quad \mathrm{k}_{\mathrm{D}}$ is related to the people evacuation behaviour and its coordination.

In so doing the planning and training can be used to build a matrix that describes the preparedness effect on the number of deaths.

\begin{tabular}{ccccc}
\hline \multirow{2}{*}{$\boldsymbol{\delta}_{\mathbf{t}}$} & \multicolumn{3}{c}{ Training (kd) } \\
\cline { 2 - 5 } Plan & Yearly & Yes & No \\
\cline { 2 - 4 }$\left(\mathrm{ks}_{\mathrm{S}}\right)$ & Yes & 0.35 & 0.73 & 1.00 \\
\cline { 2 - 4 } & Detailed & 0.15 & 0.15 & 0.15 \\
\hline
\end{tabular}

Table 8: $\delta_{\mathrm{t}}$ evaluation

\section{$5.2 \quad \delta_{p}:$ Preparedness - Evacuation efficiency around the asset}

The second aspect of preparedness that is considered is related to the around community preparedness. This resilience coefficient is very important to fit the real number of people heated by a hazardous event. It is known from the literature that exists a relation between the warning time and the percentage of people evacuated from a certain area.

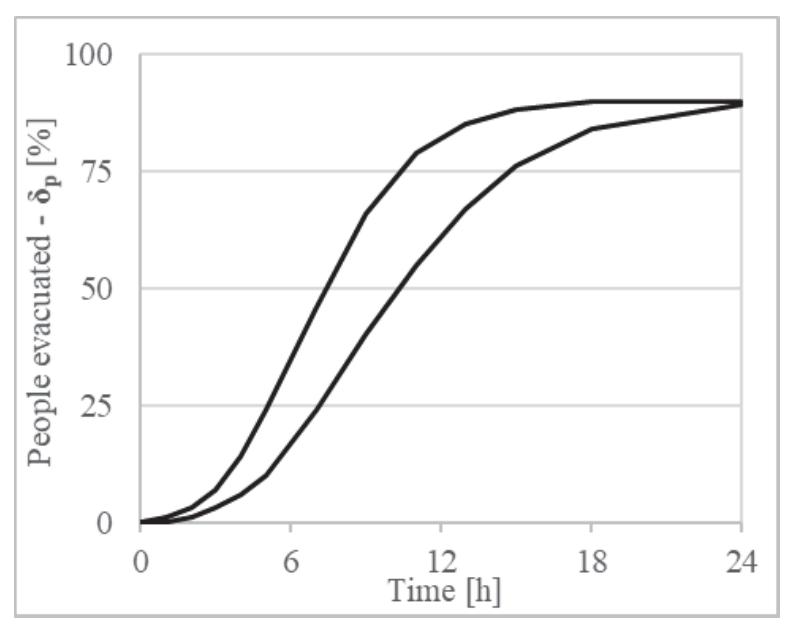

Figure 5: Example of evacuation curves 
This quite wide range can be attributed to the community capacity to react to a determined hazardous event. This aspect can be related to the so-called community experience. A community that has already experienced a certain event should have a better reaction capacity.

Therefore, the two boundaries find in literature [11] can be associated with ones of the community experience, namely less than 10 years and more the 100 years. Successively the other values can be included in the just mentioned two boundaries.

\begin{tabular}{|c|c|c|c|c|c|}
\hline & \multirow{2}{*}{$\delta_{\mathrm{p}}$} & \multicolumn{4}{|c|}{ Community experience } \\
\hline & & $>100$ years & $<100$ years & $<50$ years & $<10$ years \\
\hline \multirow{4}{*}{ 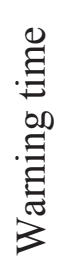 } & $<1$ hour & 0.003 & 0.007 & 0.010 & 0.007 \\
\hline & $<12$ hours & 0.615 & 0.680 & 0.746 & 0.824 \\
\hline & $<1$ day & 0.885 & 0.891 & 0.897 & 0.900 \\
\hline & $>1$ day & 0.900 & 0.900 & 0.900 & 0.900 \\
\hline
\end{tabular}

Table 9: $\delta_{\mathrm{p}}$ evaluation

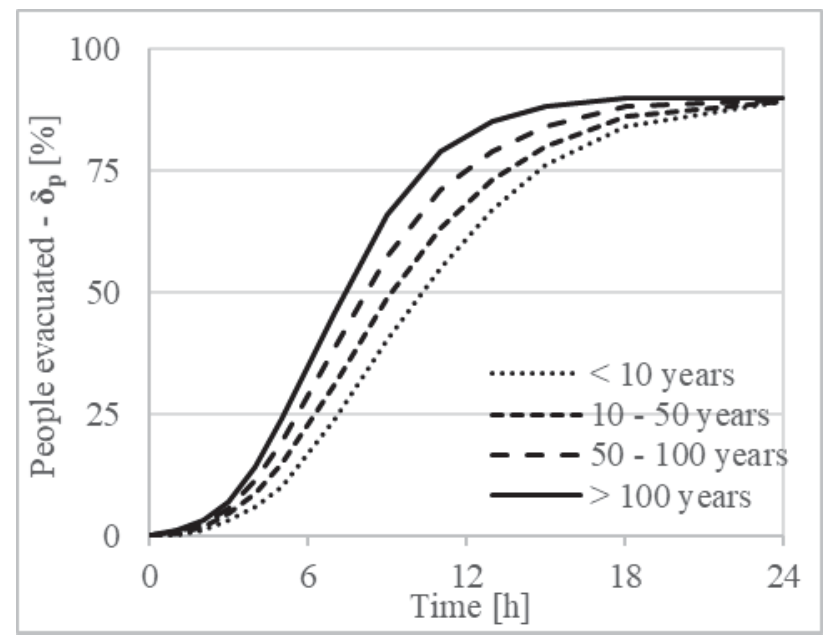

Figure 6: $\delta_{\mathrm{p}}$ evaluation

\section{3 $\delta_{\text {rec: }}$ Recovery efficiency}

During the aftermath of the event impact, an important role is played by the recovery efficiency. This efficiency has an important role in the way in which the recovery is carried out.

The recovery coefficient is set to consider the changing recovery performance during the aftermath period. This variation is related to the internal resourcefulness and preparedness of the assets according to Cimellaro et al.[1].

Since the recovery economic loss is related to the unserved characteristic in a certain period. Therefore, the coefficient is simply evaluated as the reciprocal of the area under the recovery function.

$$
\delta_{r e c, i}=\int 1-f_{r e c}(t) d t
$$




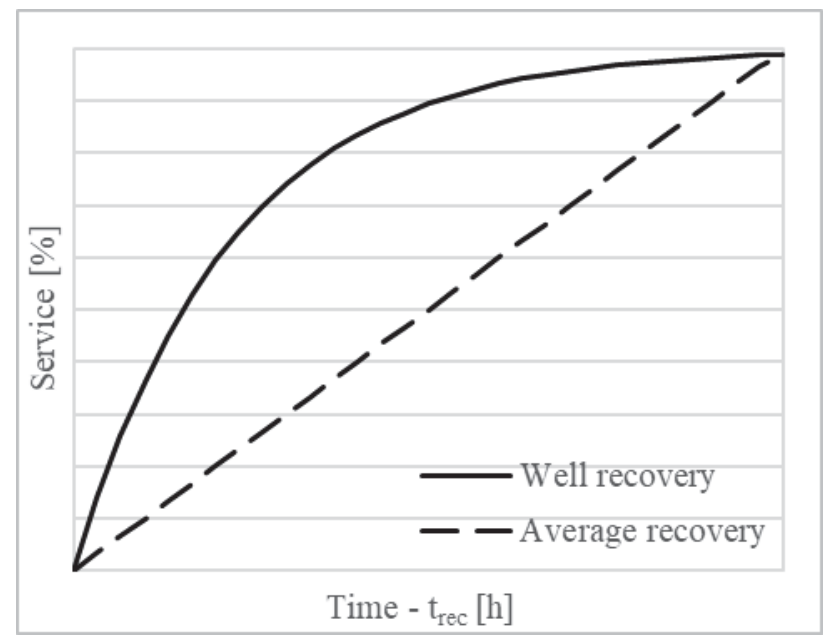

Figure 7: $\delta_{\text {rec }}$ evaluation

Two different values of $\delta_{\text {rec,i }}$ are defined, which are the lower 0.19 (well) and upper 0.5 (average and not-well) bound. The coefficient varies linearly between these two limits. To obtain the exact value, the average score of the above-mentioned question should be computed, the scoring value varies from 0 to 3 .

$$
\delta_{\text {rec }}=\delta_{\text {rec,up }}-\frac{\text { Avg Score }}{3} \cdot\left(\delta_{\text {rec }, \text { up }}-\delta_{\text {rec, down }}\right)
$$

As shown in the following table an average scoring can be computed.

\begin{tabular}{cccc}
\hline $\begin{array}{c}\text { Internal resourcefulness } \\
\& \text { preparedness }\end{array}$ & $\begin{array}{c}\text { Material to offset } \\
\text { the loss }\end{array}$ & Backup system & $\begin{array}{c}\text { Warning System } \\
\text { / Measures }\end{array}$ \\
\hline No & 0 & 0 & 0 \\
\hline Yes Partly & 1 & 3 & 3 \\
\hline Yes Full & 3 & 3 & 3 \\
\hline
\end{tabular}

Table 10: $\delta_{\text {rec }}$ evaluation

\section{$5.4 \quad \delta_{\text {int: }}$ Internal resourcefulness}

In the specific case of the analysis on the event impact on the hospital another coefficient should be considered. More precisely the internal resourcefulness should be considered.

This coefficient is called $\delta_{\text {int }}$ and it considers the goodness of the internal coordination among facilities and department. This coefficient is the merge of two different factors $\alpha$ and $\beta$ that describe the organizational and the human component during emergencies, according to Syner-G [2]. The coefficient represents the capacity of the hospital system to increase its treatment capacity during the emergency.

Since in the treatment capacity formula is inserted as $1 / \delta_{\text {int }}$, the lowest in the value, the highest is the capacity. Therefore, if the increased capacity is not ensured then the coefficient is set equal to 1 , while it is equal to 0.57 . This value is carried out according to Italian increase capacity in terms of treatment capacity during the Italian 2020 healthcare crisis, according to the data given by the Italian Ministry of Health [12]. Such a document underlined the increasing treatment capacity of $75 \%$ in the most affected regions. The value can be defined as follow:

- Existence of coordination with facilities/departments of the hospital - $\delta_{\text {int }}=0.57$.

- Not existence of coordination with facilities/departments of the hospital $-\delta_{\text {int }}=1$. 


\section{$5.5 \delta_{\mathrm{E} 1}$ : External resourcefulness - Institution efficiency}

An important aspect that should be considered is the external resourcefulness, especially related to the institution efficiency. The coefficient, in this case, can be related to the accessibility to the eventual mobile healthcare post, which can ensure a certain level of treatment capacity despite the service reduction due to the damage experienced. Therefore, $\delta_{\mathrm{E} 1}$ can be set according to the scheme shown in the following table.

\begin{tabular}{cccc}
\hline \multirow{2}{*}{$\delta_{\mathrm{E} 1}$} & \multicolumn{3}{c}{$\begin{array}{c}\text { Agreements with organ- } \\
\text { ization/institutions }\end{array}$} \\
\cline { 2 - 4 } & & Yes & No \\
\hline Local government & Yes & 1 & 0.5 \\
\cline { 2 - 4 } coordination & No & 0.5 & 0 \\
\hline
\end{tabular}

Table 11: $\delta_{\mathrm{E} 1}$ evaluation

The value of this parameter is defined initially as a Boolean function if both the question leads to a positive effect leads is equal to 1 , or 0 otherwise. If the two questions have opposite answered the half is taken.

\section{6 $\delta_{E 2}:$ External resourcefulness - Care system efficiency}

An important aspect that should be considered is the external resourcefulness, especially related to the health care system efficiency, at the interhospital level. The coefficient, in this case, can be related to hospital redistribution capacity during an emergency. Therefore, $\delta_{\mathrm{E} 2}$ can be set according to the scheme shown in the following table.

\begin{tabular}{cccc}
\hline \multirow{2}{*}{$\delta_{\mathrm{E} 2}$} & \multicolumn{2}{c}{$\begin{array}{c}\text { Health directorate } \\
\text { coordination }\end{array}$} \\
\cline { 2 - 4 } & & Yes & No \\
\hline Coordination & Yes & 1 & 0.5 \\
\cline { 2 - 4 } among hospitals & No & 0.5 & 0 \\
\hline
\end{tabular}

Table 12: $\delta_{\mathrm{E} 2}$ evaluation

The value of this parameter is defined initially as a Boolean function if both the question leads to a positive effect leads is equal to 1 , or 0 otherwise. If the two questions have opposite answered the half is taken.

\section{PROBABILITY OF DAMAGE OCCURRENCE}

In this paragraph, the hazard and vulnerability properties are combined to obtain the value of the probability of occurrence of a certain damage state. The results of this combination are representing the probability of occurrence of the impact.

The Damage probability per each damage state $\left(\mathrm{P}_{\mathrm{D}}\right)$ can be computed as the convolution integral between the Hazard curve, if available, and the fragility curves of the limit state DS.

$$
P_{D, D S i}=\int_{0}^{+\infty} F_{R, D S i}(I M) * H_{S}(I M) d(I M)
$$

Where $F_{R}$ represents the fragility curve and $H_{S}$ the hazard curve, both expressed as a function of IM (PGA [g] for earthquake). 

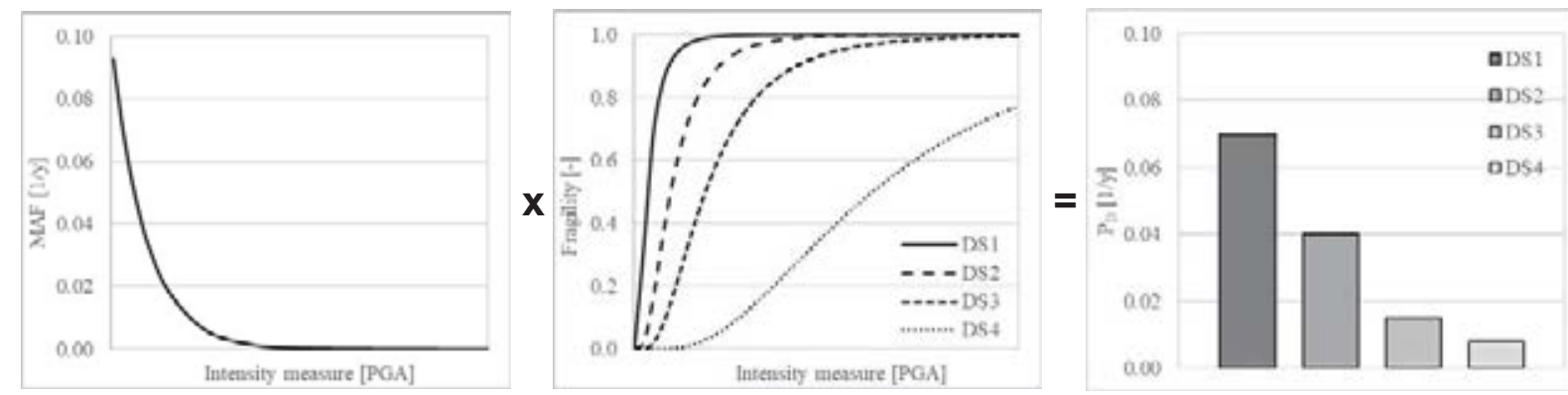

Figure 8: Damage probability per each DS

If the hazard curve is not available, which means that is unknown the occurrence probability of all the intensity measures but only of some of them, the approach is the one shown below.

$$
\left.P_{D}=\sum_{t=1}^{n} F_{t-1} M A F_{t-1}\left(1-\exp \left(m_{t} \Delta I M_{t}\right)\right)-\frac{\Delta F_{i}}{\Delta I M_{i}} M A F_{t-1}\left(\exp \left(m_{t} \Delta I M_{t}\right)\left(\Delta I M_{t}-\frac{1}{m_{i}}\right)+\frac{1}{m_{i}}\right)\right)
$$

In which:

- $\Delta I M_{i}=I M_{i}-I M_{i-1}$;

- $F_{i}=F_{i}-F_{i-1}$, in which $F(S)$ is the fragility cumulative lognormal distribution function;

- $m_{i}=\frac{\ln \left(\frac{M A F_{I}}{M A F_{L-1}}\right)}{\Delta I M_{I}}$, that is the angular coefficient of the MAF curve;

- $a_{i}=M A F_{i-1}\left(1-\exp \left(m_{i} \Delta I M_{i}\right)\right)$;

- $b_{i}=\frac{M A P_{1-1}}{\Delta I M_{I}}\left(\exp \left(m_{i} \Delta I M_{i}\right)\left(\Delta I M_{i}-\frac{1}{m_{l}}\right)+\frac{1}{m_{l}}\right)$.

\section{EXPECTED ANNUAL LOSS}

The last step of this study consists of the definition of the Expected Annual Loss (EAL). EAL is used in this methodology as the quantification of the risk level. This final value considers all the different component of the risk assessment theory, such as the probability of damage occurrence (Hazard and Vulnerability) and the total impact (Impact and Resilience).

The EAL, which can be built using the total impact and the damage (Figure 9).
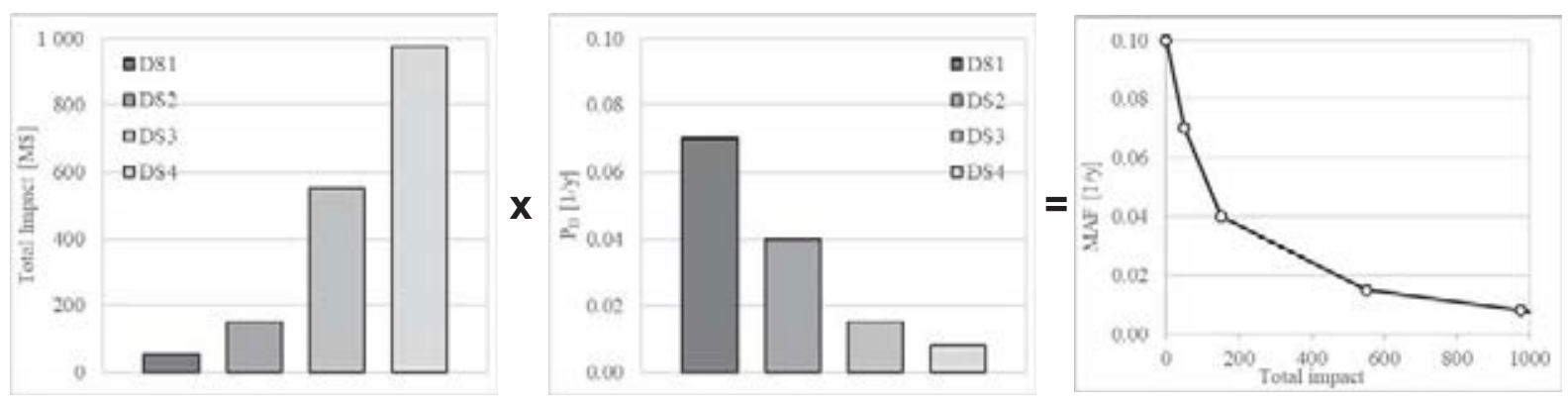

Figure 9: EAL evaluation

Finally, the area under the EAL curve is computed. This kind of results gives a unique value representing the loss of the assets per year for the considered hazard. 


$$
E A L=\sum_{i=1}^{n} \frac{\left(I_{T O T, D S(i+1)}-I_{T O T, D S i}\right)\left(P_{D, D S(i+1)}+P_{D, D S i}\right)}{2}
$$

In which $P_{D}$ is the Mean Annual Frequency (MAF) and $I_{T O T}$ is the impact loss. Therefore, the EAL is the final measure of the risk per a certain asset, subjected to an earthquake.

\section{CONCLUSIONS}

A procedure for the seismic risk assessment of hospital buildings has been presented. The following advantages are worth to be highlighted:

- The framework can be extended to the assessment of different hazards. This is mainly related to the fact that the approach used in the hazard evaluation can be used for whichever kind of natural hazard that can be expressed as an intensity measure (i.e. acceleration for earthquake, wind speed for a hurricane, water height for flood etc...) as a function of a probability of occurrence.

- This procedure is capable to compare different assets, thanks to the computation of the economic value of the risk, known as the expected annual loss (EAL) which is derived from the calculated total impact and the probability of damage occurrence (hazard + vulnerability). The result is a scalar value, computed as the area under the loss curve (Figure 9), that should be used to compare the risk among the different assets.

- The Impact is defined by considering the presence of people, livelihoods, species or ecosystems, environmental functions, services, and resources, infrastructure, or economic, social, or cultural assets in places and settings that could be adversely affected by a seismic hazard. Thus impact is normally quantified as the consequence of damages and losses caused to stakeholders, to the environment and human life. The analysis of the impact is consequently based on the definition of 3 loss categories: Impacts on People, impacts on the Physical System/Infrastructure, and Impacts on Service continuity. The consideration of all these different aspects of the impact leads to a real representation of the current value of the critical infrastructure sectors.

- The already mentioned criticality level should be defined uniquely. In so doing each level, labelled DS1, DS2, DS3, and DS4, represent always the same damage state, per each asset analysed.

- The losses are evaluated as a function of time as can be appreciated in the impact analysis. This is mainly related to the concept of damage and service which can be recovered in a certain time, called recovery time. How the impact is assessed permit also to take into account the resilience as a coefficient able to affect the recovery function.

\section{REFERENCES}

[1] G.P. Cimellaro, A.M. Reinhorn, M. Bruneau. "Seismic resilience of a hospital system". Structure and Infrastructure Engineering, Vol.6, 2010.

[2] Syner-G. "D6.7 Application and validation study to a hospital facility (Italy)". Systemic Seismic Vulnerability and Risk Analysis for Buildings, Lifeline Networks and Infrastructures Safety Gain, 2012. 
[3] A.J. Kappos, G. Panagopoulos, C. Panagiotopoulos, G. Penelis. "A hybrid method for the vulnerability assessment of R/C and URM buildings". Bulletin of Earthquake Engineering, 4:391-413. 2006

[4] World Bank Group. "How Power Investments Contribute to Jobs and Economic Growth in Turkey". 2017.

[5] FEMA. "Hazus-MH2.1 - Multihazard Loss Estimation Methodology - Earthquake Model Technical Manual”. 2013.

[6] M.L. Sousa, G. Tsionis. "Recommendation for a National Risk Assessment for Disaster Risk Management in EU - Approaches for identifying, analysing and evaluating risk". JRC Science for policy report. Version 0. Cap.9, 56-67. 2019.

[7] Syner-G. "D3.1 - Fragility functions for common RC building types in Europe". Systemic Seismic Vulnerability and Risk Analysis for Buildings, Lifeline Networks and Infrastructures Safety Gain. 2011.

[8] E. Ulutas, M.F. Ozer. "Empirical attenuation relationship of peak ground acceleration for eastern Marmara region in Turkey". The Arabian Journal for Science and Engineering, 35, 1ㅇ, 187-203. 2010.

[9] R. E. Fisher, G. W. Bassett, W. A. Buehring, M. J. Collins, D.C. Dickinson, L.K. Eaton, D.J. Millier. "Constructing a resilience index for the enhanced critical infrastructure protection program". Argonne Decision and Information Sciences. 2010.

[10] S. Li, C. Zhai, L. Xie. "Occupant evacuation and casualty estimation in a building under earthquake using cellular automata". Physica A: Statistical Mechanics and its Applications, 424, 152-167. 2015.

[11] S. N. Jonkman. "Loss of life estimation in flood risk assessment; theory and applications". 2007.

[12] Italian Ministry of Healt. 0007865-25/03/2020-DGPROGS-MDS-P, Aggiornamento delle linee di indirizzo organizzative dei servizi ospedalieri e territoriali in corso di emergenza COVID-19. 2020. (in italian)

[13] https://www.ilsole24ore.com/art/coronavirus-1865-nuovi-contagi-e-76-mortilombardia-AD40iMD Last accessed 28/07/2020. (in Italian)

[14] https:/www.naffco.com/uae/en/products/mobile-medical-units Last accessed $21 / 05 / 2020$. 